논문 2019-2-10 http://dx.doi.org/10.29056/jsav.2019.12.10

$$
\begin{gathered}
\text { 항공기 음성인식 소프트웨어 품질 평가 모델 연구 } \\
\text { 이승목*中 }
\end{gathered}
$$

\title{
The Study on the Quality Assessment Model of Aircraft Voice Recognition Software
}

\author{
Seung-Mok Lee**
}

요 약

음성인식은 최근 인공지능 기술과 접목되면서 오인식률이 크게 개선되었고 사용자 관점에서 효과적이고 효율적인 HMI(Human Machine Interface)를 제공하고 있다. 이러한 추세는 방위산업 분야에서도 반영되고 있 고 특히 항공분야에서 $\mathrm{F}-35$ 에 적용이 되었다. 하지만 이러한 기술에 대해서 품질평가를 위해 방위산업 특히 항공분야에는 객관적이고 평가 가능한 정량적인 모델이 필요하다.

본 연구에서는 이러한 음성인식의 소프트웨어 측면에서 항공기에 적용하기 위한 정량적인 평가 모델을 제 시한다. 평가 모델 제시를 위해 음성인식 적용 기술과 ISO/IEC 25000(SQuaRE) 제품 품질 속성을 이용해 평 가 항목을 추출한다. 이러한 두 가지 항목의 연계를 통해 정량적인 평가 모델을 제시하고 사례 연구를 활용 해 평가 결과를 확인한다.

\begin{abstract}
Voice Recognition has recently been improved with AI(Artificial Intelligence) and has greatly improved the false recognition rate and provides an effective and efficient Human Machine Interface (HMI). This trend has also been applied in the defense industry, particularly in the aviation, F-35. However, for the quality evaluation of Voice Recognition, the defense industry, especially the aircraft, requires measurable quantitative models.

In this paper, the quantitative evaluation model is proposed for applying Voice Recognition to aircraft. For the proposal, the evaluation items are identified from the Voice Recognition technology and ISO/IEC 25000(SQuaRE) quality attributes. Using these two perspectives, the quantitative evaluation model is proposed under aircraft operation condition and confirms the evaluation results.
\end{abstract}

한글키워드 : 음성인식, 품질평가, 항공전자, 정량적 평가, 품질모델

keywords : Voice Recognition, Quality Evaluation, Avionics, Quantitative Evaluation, Quality Model

\section{1. 서 론}

* 한화시스템 항공전자연구센터

† 교신저자: 이승목(email: seungmok23.lee@hanwha.com) 접수일자: 2019.11.08. 심사완료: 2019.11.27. 게재확정: 2019.12.20.
최근 인공지능 기술의 발달로 음성인식은 급 속도로 발전했다. 딥러닝, 머신러닝과 같은 $\mathrm{AI}$ 기 술이 활용되면서부터 음성인식 오류율이 낮아지 고 본격적인 상용화가 이루어지고 있다[1]. 주요 사례로 애플의 인공지능 음성인식 서비스인 시리 
(Siri)는 사용자가 음성으로 명령을 내리면 그 명 령을 해석해서 아이폰, 혹은 아이패드에 설치되 어있는 앱들을 이용하여 검색하여 그 결과를 보 여주거나 앱을 실행한다[2]. 음성인식 가상비서 서비스도 최근 활발히 출시되고 있는데 네이버는 자체 $\mathrm{AI}$ 플랫폼인 클로버(Clover) 기반의 웨이브 (WAVE), 캐릭터를 반영한 프렌즈를, 카카오는 카카오톡과 연계된 카카오 미니를 출시하였다. 삼성전자는 음성비서 빅스비(Bixby)를 탑재한 스 피커를 2018년에 출시하였다[3].

게다가 음성명령은 같은 문장을 텍스트로 입 력하는 방식 대비 크기 2.8배[3]의 효율성을 제공 함에 따라 사용자 관점에서 효과적인 HMI(Human Machine Interface)를 제공한다.

이러한 음성인식은 방위산업기술에도 적용되 는 추세이다. 특히 항공기에서 조종사의 업무 및 임무 부하를 감소시켜 임무수행에 큰 역할을 수 행할 수 있다. 이러한 장점으로 인해 최근 미국 최신 전투기 $\mathrm{F}-35$ 에도 적용되었다[4].

하지만 항공분야는 높은 수준의 신뢰성과 안 전성을 확보하여야[5] 하므로 음성인식이 적용될 경우 해당 품질평가 시 이러한 요소가 반영되어 야 한다. 이러한 특성이 미 반영될 경우 조종사 의 임무 수행 시 조종사 편의사항이 오히려 제약 사항으로 전락될 수 있다. 또한, 품질평가를 위해 서 수치적으로 표현이 되는 정량적인 평가를 통 해 객관적인 검증과 품질 비교가 가능해야 한다.

본 논문은 항공기에 음성인식을 적용함에 있 어 음성인식 평가를 위한 정량적인 품질 평가 모 델을 제시한다. 2장은 음성인식 기술 연구를 통 해 음성인식 기술과 ISO/IEC 25000 소프트웨어 제품 품질속성을 통해 평가 항목을 분석한다. 3 장에서는 2장에서 분석한 각 요소를 기반으로 항 공기용 음성인식 소프트웨어 품질 평가 요소를 식별, Metric을 정의하고 사례 연구를 통해 확인 한 후 4장에서 결론을 맺는다.

\section{2. 관련 연구}

\section{1 음성인식 기술 관련 연구}

음성인식 기술은 그림 1 과 같이 전처리, 특징 추출, 음성모델을 이용한 거리계산, 음성모델 학 습을 통한 $\mathrm{DB}$ 의 4 가지 단계를 거쳐 아날로그의 음성을 디지털적으로 해석할 수 있다.

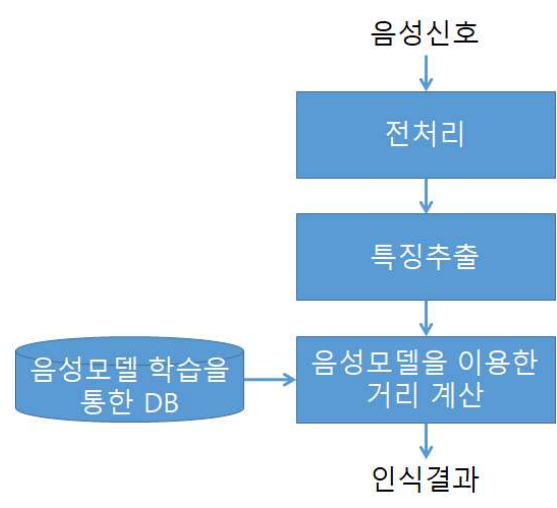

그림 1. 음성인식 기술의 원리[6]

Fig 1. Theory of Voice Recognition

표 1 과 같이 음성인식은 크게 처리/가공단계, 학습/인식 단계로 나눌 수 있다. 처리/가공단계에 서는 1. 음성에 대한 아날로그 성분을 추출 후 특징분석에 용이하도록 전처리를 수행하고 2. 전 처리기로부터 받은 자료를 기반으로 데이터 해석 을 위해 적절한 변환과 관련 특징을 추출한다. 학습/인식 단계에서는 3. 모델을 통해 특징간 거 리 연산으로 가장 근접한 단어/글자와 사상을 시 킨다. 4. 사상을 시키면서 수행된 학습모델을 저 장 및 $\mathrm{DB}$ 화함으로써 학습한다. 이러한 4단계의 단계를 거쳐 사용자의 음성에 대해 인식결과 값 을 출력한다.

음성인식을 위한 처리/가공 단계에서 소요되는 기술은 표 2와 같다. 
표 1. 음성인식 처리 단계별 설명

Table 1. The Explanation of

Voice Recognition Process

\begin{tabular}{|c|c|c|}
\hline $\begin{array}{l}\text { 구 } \\
\text { 분 }\end{array}$ & 단계[6] & 내용 \\
\hline $\begin{array}{l}\text { 처 } \\
\text { 리/ } \\
\text { 가 } \\
\text { 공 }\end{array}$ & 1. 전처리 & $\begin{array}{l}\text { - 음성의 방향 감지 및 감 } \\
\text { 지율 최대화 } \\
\text { - 아날로그를 디지털로 전 } \\
\quad \text { 환 }\end{array}$ \\
\hline $\begin{array}{l}\text { 단 } \\
\text { 계 }\end{array}$ & $\begin{array}{l}\text { 2. 특징 } \\
\text { 추출 }\end{array}$ & $\begin{array}{l}\text { - 데이터 기반을 둔 특징 } \\
\text { 추출 }\end{array}$ \\
\hline $\begin{array}{l}\text { 학 } \\
\text { 습/ } \\
\text { 인 } \\
\text { 식 }\end{array}$ & $\begin{array}{l}\text { 3. 음성 } \\
\text { 모델을 } \\
\text { 이용한 } \\
\text { 거리계산 }\end{array}$ & $\begin{array}{l}\text { - 추출된 특징에 기반을 } \\
\text { 둔 음성모델간 거리 측 } \\
\text { 정 } \\
\text { - 거리 기반의 최근접 단 } \\
\text { 어 검색 }\end{array}$ \\
\hline $\begin{array}{l}\text { 단 } \\
\text { 계 }\end{array}$ & $\begin{array}{l}\text { 4. 음성모델 } \\
\text { 학 습 을 } \\
\text { 통한 } \mathrm{DB}\end{array}$ & $\begin{array}{l}\text { - 거리 계산 등의 학습모 } \\
\text { 델을 저장 및 } \mathrm{DB} \text { 화 }\end{array}$ \\
\hline
\end{tabular}

전처리에서 사용되는 기술에서는 외부환경에 대해서 음성인식 대상만 정확하고 효율적으로 추 출해야 한다. 특징추출에서 사용되는 기술은 판 단이 용이하기 위한 특징데이터를 변환하고 변환 시 짧은 시간소요가 핵심이다. 음향모델, 모델학 습 및 인식 알고리즘 또한 정확한 음성인식을 위 해 빠르고 정확한 학습이 중요하다.

\section{2 소프트웨어 품질 특성에 관한 연구}

ISO/IEC 25000의 SQuaRE(Software product Quality Requirements and Evaluation) 아키텍처 는 소프트웨어 제품품질과 관련한 표준을 정의하 고 있다[7]. 이러한 SQuaRE 아키텍처는 그림 2 와 같은 소프트웨어 품질 평가 모델을 제시하고 있다[7].
표 2. 음성인식의 적용 기술[6]

Table 2. Tech. Applied to Voice Recognition

\begin{tabular}{|c|c|c|}
\hline 구분 & 기술 & 설명 \\
\hline \multirow{2}{*}{$\begin{array}{l}\text { 전처 } \\
\text { 리 }\end{array}$} & $\begin{array}{l}\text { 음성 } \\
\text { 방향 } \\
\text { 추정 }\end{array}$ & $\begin{array}{l}\text { - 음성의 발성 방향을 감지 } \\
\text { 하고 음성 감지 효율을 최 } \\
\text { 대화 }\end{array}$ \\
\hline & $\begin{array}{l}\text { 빔 } \\
\text { 포밍 }\end{array}$ & $\begin{array}{l}\text { - 음성이 효과적으로 수신 } \\
\text { 하기 위해 위상차를 이용한 } \\
\text { 신호처리 }\end{array}$ \\
\hline \multirow{2}{*}{$\begin{array}{l}\text { 특징 } \\
\text { 추출 }\end{array}$} & STFT & $\begin{array}{l}\text { - Short Time Fourier } \\
\text { Transform } \\
\text { - } 10 \mathrm{msec}, 25 \mathrm{msec} \text { 단위의 } \\
\text { 퓨리에 변환 }\end{array}$ \\
\hline & DCT & $\begin{array}{l}\text { - Discrete Cosine } \\
\text { Transform } \\
\text { - 명확한 특징 추출을 위한 } \\
\text { 변환 }\end{array}$ \\
\hline \multirow[t]{2}{*}{$\begin{array}{l}\text { 음향 } \\
\text { 모델 }\end{array}$} & HMM & $\begin{array}{l}\text { - Hidden Markov Model } \\
\text { - 음성, 이미지, 비 } \\
\text { 디오, 음악, 금융 데이터와 } \\
\text { 같은 시간적 또는 공간적 } \\
\text { 계열 데이터 표현하는데 자 } \\
\text { 주 사용 }\end{array}$ \\
\hline & GMM & $\begin{array}{l}\text { - Gaussian mixture model } \\
\text { - HMM에서 관측벡터를 } \\
\text { 표현 }\end{array}$ \\
\hline \multirow{2}{*}{$\begin{array}{l}\text { 모델 } \\
\text { 학습 } \\
\text { 및 } \\
\text { 인식 } \\
\text { 알고 } \\
\text { 리즘 }\end{array}$} & $\begin{array}{l}\mathrm{EM} \\
\text { 알고 } \\
\text { 리즘 }\end{array}$ & $\begin{array}{l}\text { - E-step : 모르는 변수에 } \\
\text { 대한 사후확률을 추정하여 } \\
\text { 목적함수의 기대치를 정의 } \\
\text { - M-step : 목적함수의 기 } \\
\text { 대치를 최대화하는 파라미 } \\
\text { 터를 추정 }\end{array}$ \\
\hline & $\begin{array}{l}\text { Viterbi } \\
\text { 알고 } \\
\text { 리즘 }\end{array}$ & $\begin{array}{l}\text { - 관측신호의 } \mathrm{n} \text { 번째 상태 } \\
\text { 에 대한 Viterbi score를 측 } \\
\text { 정 }\end{array}$ \\
\hline
\end{tabular}




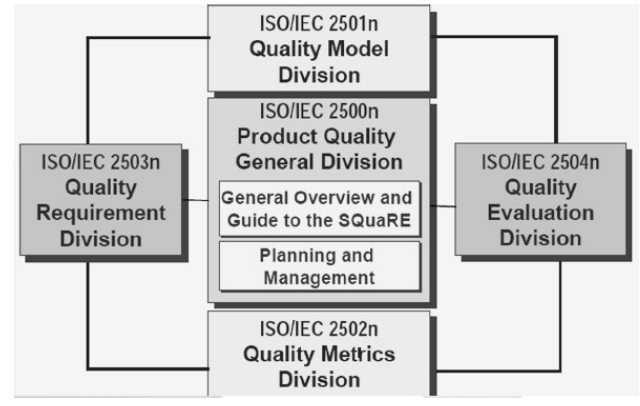

그림 2. SQuaRE 아키택처[8]

Fig 2. SQuaRE Architecture

ISO/IEC 25000의 제품 품질속성은 기능 적합 성, 성능 효율성, 호환성, 사용성, 신뢰성, 보안, 유지보수성, 이식성의 8가지 요소로 구분되며 제 품 품질 속성에 대한 상세 설명은 표 3 과 같다.

표 3. ISO/IEC 25000 제품 품질 속성 개요[7] Table 3. ISO/IEC 25000 Production Quality Attributes Overview

\begin{tabular}{|c|c|c|}
\hline $\begin{array}{l}\text { 주요 } \\
\text { 속성 }\end{array}$ & 구분 & 내용 \\
\hline \multirow{2}{*}{$\begin{array}{l}1 . \\
\text { 기능 } \\
\text { 적합 } \\
\text { 성 }\end{array}$} & 설명 & $\begin{array}{l}\text { 제품 또는 시스템이 지정된 조건 } \\
\text { 에서 사용될 때 명시적 및 암시적 } \\
\text { 요구를 충족시키는 기능을 제공하 } \\
\text { 는 정도 }\end{array}$ \\
\hline & $\begin{array}{l}\text { 하위 } \\
\text { 속성 }\end{array}$ & $\begin{array}{l}\text { 1.1. 기능 완전성 } \\
\text { 1.2. 기능적 정확성 } \\
\text { 1.3. 기능적 적절성 }\end{array}$ \\
\hline \multirow{2}{*}{$\begin{array}{l}2 . \\
\text { 성능 } \\
\text { 효율 } \\
\text { 성 }\end{array}$} & 설명 & $\begin{array}{l}\text { 명시된 조건에서 사용되는 자원량 } \\
\text { 과 관련된 성능 }\end{array}$ \\
\hline & $\begin{array}{l}\text { 하위 } \\
\text { 속성 }\end{array}$ & $\begin{array}{l}\text { 2.1. 시간 효율성 } \\
\text { 2.2. 자원 효율성 } \\
\text { 2.3. 사양 }\end{array}$ \\
\hline $\begin{array}{l}3 . \\
\text { 호환 } \\
\text { 성 }\end{array}$ & 설명 & $\begin{array}{l}\text { 제품, 시스템 또는 컴포넌트가 다 } \\
\text { 른 제품, 시스템 또는 컴포넌트간 } \\
\text { 정보를 상호교환할 수 있거나 같 } \\
\text { 은 하드웨어/소프트웨어 환경을 } \\
\text { 공유하는 동안 요구되는 기능을 } \\
\text { 수행하는 정도 }\end{array}$ \\
\hline
\end{tabular}

\begin{tabular}{|c|c|c|}
\hline $\begin{array}{l}\text { 주요 } \\
\text { 속성 }\end{array}$ & 구분 & 내용 \\
\hline & $\begin{array}{l}\text { 하위 } \\
\text { 속성 }\end{array}$ & $\begin{array}{l}\text { 3.1. 공존성 } \\
\text { 3.2. 상호운용성 }\end{array}$ \\
\hline \multirow[b]{2}{*}{$\begin{array}{l}4 . \\
\text { 사용 } \\
\text { 성 }\end{array}$} & 설명 & $\begin{array}{l}\text { 특정 사용자가 제품 또는 시스템 } \\
\text { 을 사용하여 지정된 사용 환경에 } \\
\text { 서 효과, 효율성 및 만족도로 지정 } \\
\text { 된 목표를 달성 할 수 있는 정도 }\end{array}$ \\
\hline & $\begin{array}{l}\text { 하위 } \\
\text { 속성 }\end{array}$ & $\begin{array}{l}\text { 4.1. 적절하다고 느끼는 정도 } \\
\text { 4.2. 학습성 } \\
\text { 4.3. 조장성 } \\
\text { 4.4. 사용자 오류 방지 } \\
\text { 4.5. 사용자 인터페이스 미학 } \\
\text { 4.6. 접근성 }\end{array}$ \\
\hline \multirow{2}{*}{$\begin{array}{l}5 . \\
\text { 신뢰 } \\
\text { 성 }\end{array}$} & 설명 & $\begin{array}{l}\text { 시스템, 제품 또는 구성 요소가 지 } \\
\text { 정된 기간 동안 지정된 조건에서 } \\
\text { 특정 기능을 수행하는 정도 }\end{array}$ \\
\hline & $\begin{array}{l}\text { 하위 } \\
\text { 속성 }\end{array}$ & $\begin{array}{l}\text { 5.1. 성숙성 } \\
\text { 5.2. 사용가능성 } \\
\text { 5.3. 결함 허용성 } \\
\text { 5.4. 복구성 }\end{array}$ \\
\hline \multirow{2}{*}{$\begin{array}{c}6 . \\
\text { 보안 }\end{array}$} & 설명 & $\begin{array}{l}\text { 개인이나 다른 제품 또는 시스템 } \\
\text { 이 해당 유형 및 권한 수준에 적합 } \\
\text { 한 데이터 액세스 권한을 갖도록 } \\
\text { 제품 또는 시스템을 보호하는 정 } \\
\text { 도 }\end{array}$ \\
\hline & $\begin{array}{l}\text { 하위 } \\
\text { 속성 }\end{array}$ & $\begin{array}{l}\text { 6.1. 기밀성 } \\
\text { 6.2. 무결성 } \\
\text { 6.3. 부인방지 } \\
\text { 6.4. 책임성 } \\
\text { 6.5. 인증 } \\
\end{array}$ \\
\hline \multirow{2}{*}{$\begin{array}{l}7 . \\
\text { 유지 } \\
\text { 보수 } \\
\text { 성 }\end{array}$} & 설명 & $\begin{array}{l}\text { 유지보수자가 제품 또는 시스템을 } \\
\text { 수정할 수 있는 효과 및 효율성의 } \\
\text { 정도 }\end{array}$ \\
\hline & $\begin{array}{l}\text { 하위 } \\
\text { 속성 }\end{array}$ & $\begin{array}{l}\text { 7.1. 모듈성 } \\
\text { 7.2. 재사용성 } \\
\text { 7.3. 분석성 } \\
\text { 7.4. 변경성 } \\
\text { 7.5. 시험성 }\end{array}$ \\
\hline
\end{tabular}




\begin{tabular}{|c|c|c|}
\hline $\begin{array}{l}\text { 주요 } \\
\text { 속성 }\end{array}$ & 구분 & 내용 \\
\hline \multirow[t]{2}{*}{$\begin{array}{l}8 . \\
\text { 이식 } \\
\text { 성 }\end{array}$} & 설명 & $\begin{array}{l}\text { 시스템, 제품 혹은 컴포넌트가 하 } \\
\text { 나의 하드웨어, 소프트웨어 또는 } \\
\text { 타 운용/사용 환경에서 다른 곳으 } \\
\text { 로 이전할 수 있는 효과, 효율성 } \\
\text { 정도 }\end{array}$ \\
\hline & $\begin{array}{l}\text { 하위 } \\
\text { 속성 }\end{array}$ & $\begin{array}{l}\text { 8.1. 적응성 } \\
\text { 8.2. 설치성 } \\
\text { 8.3. 대체성 }\end{array}$ \\
\hline
\end{tabular}

하지만 이러한 ISO/IEC 25000 품질 속성은 소 프트웨어에서 범용적으로 활용되므로 항공기 음 성인식 품질 평가를 위해서 최적화 적용이 필요 하다.

\section{3. 항공기용 음성인식 품질 평가 모델}

\section{1 음성인식 기술을 통한 품질 평가 항목 분석}

관련 연구를 통해 식별된 음성인식 기술에 대 해서 품질 평가 요소는 각 단계별 적용되는 기술 과 접목시켜 추출할 수 있다. 기술별 평가 항목 은 표 4 와 같다.

음성인식 기술에 대해서 품질 평가를 위해 각 기술별 평가 항목의 공통점을 기능, 비기능 관점 으로 나누어 보면 기능관점은 연산/알고리즘의 정확도이고 비기능관점은 연산/알고리즘에 대해 서 수행되는 처리 속도이다. 따라서 음성인식 기 술에 대한 평가 항목은 기능 정확도와 처리 속도 로 추출할 수 있다. 또한 각각의 기술에 대해 정 확도와 처리 속도 측정이 중요하나 시스템 관점 에서 해당 음성인식 기술이 적용된 시스템 전체 정확도와 처리속도로 접근한다. 정확도는 음성 오인식율인 WER(Word Error Rate)을 활용해
품질 Metric으로 활용하고 처리 속도는 시스템 전체 음성인식 소요시간을 품질 Metric으로 활용 한다.

표 4. 음성인식 기술에 대한 품질 평가 항목 Table 4. Quality Assessment Contents for Voice Recognition

\begin{tabular}{|c|c|c|}
\hline 구분 & 기술 & 품질 평가 항목 \\
\hline \multirow{2}{*}{$\begin{array}{l}\text { 전처 } \\
\text { 리 }\end{array}$} & $\begin{array}{l}\text { 음성방향 } \\
\text { 추정 }\end{array}$ & $\begin{array}{l}\text { - 음성방향추정 시간 } \\
\text { - 음성방향추정 정확도 }\end{array}$ \\
\hline & 빔포밍 & $\begin{array}{l}\text { - 빔포밍 처리 후 원음 } \\
\text { 과의 정확도 비교 } \\
\text { - 빔포밍 처리 시간 }\end{array}$ \\
\hline \multirow{2}{*}{$\begin{array}{l}\text { 특징 } \\
\text { 추출 }\end{array}$} & STFT & $\begin{array}{l}\text { - 퓨리에 변환을 위한 } \\
\text { 단위 시간 } \\
\text { - 변환 처리 시간 }\end{array}$ \\
\hline & DCT & $\begin{array}{l}\text { - 주파수/공간영역 변환 } \\
\text { 시간 } \\
\text { - 에너지 집중 현상 구 } \\
\text { 간 감지 시간 }\end{array}$ \\
\hline \multirow{2}{*}{$\begin{array}{l}\text { 음향 } \\
\text { 모델 }\end{array}$} & HMM & $\begin{array}{l}\text { - 간적 또는 공간적 계 } \\
\text { 열 데이터 변환 처리 } \\
\text { 시간 }\end{array}$ \\
\hline & GMM & $\begin{array}{l}\text { - HMM 관측벡터 표현 } \\
\text { 시간 }\end{array}$ \\
\hline \multirow{2}{*}{$\begin{array}{c}\text { 모텔 } \\
\text { 학습 } \\
\text { 및 } \\
\text { 인식 } \\
\text { 알고 } \\
\text { 리즘 }\end{array}$} & $\begin{array}{c}\mathrm{EM} \\
\text { 알고리즘 }\end{array}$ & \multirow{2}{*}{$\begin{array}{l}\text { - 알고리즘 연산 소요 } \\
\text { 시간 } \\
\text { - 알고리즘 수행 후 연 } \\
\text { 산 정확도 }\end{array}$} \\
\hline & $\begin{array}{l}\text { Viterbi } \\
\text { 알고리즘 }\end{array}$ & \\
\hline
\end{tabular}

\subsection{ISO/IEC 25000을 통한 품질 평가 항목 분석}

ISO/IEC 25000의 품질 속성 중 항공기의 운용 환경을 고려해 표 5 와 같이 품질 속성을 연계 분 석할 수 있다. 
표 5. 항공기 특성과 ISO/IEC 25000 품질 속성간 연계 분석

Table 5. Association Analysis between Aircraft Characteristics and

ISO/IEC 25000 Quality Attributes

\begin{tabular}{|c|c|c|}
\hline $\begin{array}{l}\mathrm{ISO} / \mathrm{IEC} \\
25000 \\
\text { 품질 속성 }\end{array}$ & $\begin{array}{c}\text { 항공기 운용 } \\
\text { 특성 }\end{array}$ & $\begin{array}{l}\text { 음성인식 } \\
\text { 품질속성 }\end{array}$ \\
\hline $\begin{array}{c}1 . \\
\text { 기능 적합성 }\end{array}$ & $\begin{array}{c}\text { 조종사의 } \\
\text { 항공기 기능 } \\
\text { 운용 }\end{array}$ & $\begin{array}{l}\text { 기능 } \\
\text { 충족성 }\end{array}$ \\
\hline $\begin{array}{c}2 . \\
\text { 성능 효율성 }\end{array}$ & $\begin{array}{c}\text { 항공기의 고속 } \\
\text { 운항 }\end{array}$ & $\begin{array}{l}\text { 빠른 } \\
\text { 응답성 }\end{array}$ \\
\hline $\begin{array}{c}3 . \\
\text { 호환성 }\end{array}$ & - & - \\
\hline $\begin{array}{c}4 . \\
\text { 사용성 }\end{array}$ & $\begin{array}{l}\text { 조종사의 항공 } \\
\text { 운용 편의성 }\end{array}$ & $\begin{array}{l}\text { 사용 } \\
\text { 편리성 }\end{array}$ \\
\hline $\begin{array}{c}5 . \\
\text { 신뢰성 }\end{array}$ & $\begin{array}{l}\text { 음성인식 } \\
\text { 처리의 고 } \\
\text { 신뢰성 }\end{array}$ & $\begin{array}{l}\text { 음성인식 } \\
\text { 신뢰성 }\end{array}$ \\
\hline $\begin{array}{c}6 . \\
\text { 보안 }\end{array}$ & $\begin{array}{l}\text { 항공기 데이터 } \\
\text { 접근성 제한 }\end{array}$ & $\begin{array}{l}\text { 데이터 } \\
\text { 접근 } \\
\text { 제한성 }\end{array}$ \\
\hline $\begin{array}{c}7 . \\
\text { 유지 보수성 }\end{array}$ & - & - \\
\hline $\begin{array}{c}8 . \\
\text { 이식성 }\end{array}$ & - & - \\
\hline
\end{tabular}

항공기의 운용환경을 분석해 보면 고속 운행 환경에 노출되어 있고 조종사에 결심 및 의지에 따라 항공기 동작이 결정되며 인명과 연계되므로 안전성이 중요하다. 이를 ISO/IEC 25000 의 품질 속성과 연계해 볼 때 표 5와 같이 기능 적합성, 성능 효율성, 사용성, 신뢰성, 보안이 품질 평가 중 핵심관심사가 된다. 호환성, 유지 보수성, 이 식성도 중요한 요소이지만 이는 항공기 운용보다 는 소프트웨어 개발 관점에서 더 중요한 항목이
므로 이러한 3 가지 품질 속성은 다소 연관성이 부족하다.

즉, 항공기와 연계된 5가지 속성에 대해서 음 성인식 기술의 품질 평가항목과 품질속성에 의거 한 정량적인 지표를 기반하여 관련 Metric을 정 의, 관련 품질 평가 모델을 유도할 수 있다.

\section{3 항공기 음성인식 품질 평가 모델}

음성인식 기술의 품질 평가 항목과 항공기 특 성이 반영된 ISO/IEC 25000 품질 속성과 연계시 켜 볼 때 각 품질 평가 항목은 표 6 과 같이 상세 화 할 수 있다.

표 6. 품질 속성별 품질 평가 상세 내용 Table 6. Quality Assessment each Quality Attributes

\begin{tabular}{|c|c|c|}
\hline $\begin{array}{l}\text { ISO/IEC } \\
25000 \\
\text { 품질 속성 }\end{array}$ & $\begin{array}{l}\text { 품질 평가 } \\
\text { 상세 내용 }\end{array}$ & $\begin{array}{l}\text { 음성인식 } \\
\text { 기술과 } \\
\text { 연계성 }\end{array}$ \\
\hline $\begin{array}{c}1 . \\
\text { 기능 적합성 }\end{array}$ & $\begin{array}{l}\text { 음성인식 기능 } \\
\text { 정확성 }\end{array}$ & 0 \\
\hline $\begin{array}{c}2 . \\
\text { 성능 효율성 }\end{array}$ & $\begin{array}{l}\text { 음성인식 } \\
\text { 처리 시간 }\end{array}$ & 0 \\
\hline $\begin{array}{c}4 . \\
\text { 사용성 }\end{array}$ & $\begin{array}{l}\text { 동일 기능에 대한 } \\
\text { 기존 처리 노력 대 } \\
\text { 비 음성인식 사용에 } \\
\text { 따른 노력 효율성 }\end{array}$ & - \\
\hline $\begin{array}{c}5 . \\
\text { 신뢰성 }\end{array}$ & $\begin{array}{l}\text { 동일한 음성명령에 } \\
\text { 대한 동일한 음성인 } \\
\text { 식 결과 여부 }\end{array}$ & - \\
\hline $\begin{array}{c}6 . \\
\text { 보안 }\end{array}$ & $\begin{array}{l}\text { 음성모델 학습 } \mathrm{DB} \\
\text { 보호 여부 }\end{array}$ & - \\
\hline
\end{tabular}

표 6에 따른 평가 상세 내용에 대해서 Metric 으로 정의하면 기능 적합성 Metric은 기능적 정 확성으로 적용할 수 있다. 따라서 음성인식의 정 
확도로 정의할 수 있다. 이는 WER을 이용, WER이 오류율을 의미하므로 1 에서 오류율을 뺀 값인 정상률 값을 취한다.

성능 효율성 Metric은 자원량의 효율성, 특히 시간 효율성을 표현해야 하므로 동일 기능에 대 해서 음성인식을 이용해 처리한 시간을 기준 대 비 타 방법을 이용해 처리한 시간 비율로 정의할 수 있다. 이는 곧 음성인식의 처리 효율성을 비 율로 산정된다.

사용성 Metric은 사용자의 만족도와 같은 주 관적인 판단, 즉 정성적인 평가가 많이 반영된다. 하지만 정성적인 평가 반영을 최대한 배제하기 위해 동일한 기능 실행에 대해서 음성인식 인터 페이스 접근노력 대비 음성인식 외 방식의 인터 페이스 접근 노력에 대한 비율로 정의한다. 즉, 기존 대비 사용자 접근 편의성을 수치로 표현한 다.

신뢰성 Metric은 동일한 음성명령을 반복 주 입해 동일한 음성명령 인식 횟수를 비율로 산정 해서 적용함으로써 결과에 대한 일치성으로 신뢰 성을 측정한다.

보안 Metric은 다양한 $\mathrm{DB}$ 보안 기법이 존재하 지만 정량적으로 측정하기 위해서 암호화 보안강 도를 이용한다. 한국인터넷진흥원의 암호 알고리 즘 및 키 길이 이용 안내서에 기반, 보안강도를 기준으로 표 7과 같이 Metric을 할당한다.

표 7. 보안강도에 따른 Metric Table 7. Metric each Security Strength

\begin{tabular}{|c|c|}
\hline 보안강도[9] & Metric 할당 \\
\hline 80 비트 이상 & 0.1 \\
\hline 112 비트 이상 & 0.3 \\
\hline 128 비트 이상 & 0.5 \\
\hline 192 비트 이상 & 0.7 \\
\hline 256 비트 이상 & 1 \\
\hline
\end{tabular}

각 Metric의 정의를 통해 산출되는 Metric 수 식은 표 8과 같다.

표 8. 품질 속성별 품질 평가 Metric

Table 8. Quality Assessment Metric each Quality Attributes

\begin{tabular}{|c|c|}
\hline $\begin{array}{l}\text { 품질 } \\
\text { 속성별 } \\
\text { Metric } \\
\text { 구분 }\end{array}$ & Metric 산출 수식 \\
\hline $\begin{array}{l}\text { 기능 } \\
\text { 적합성 } \\
M_{\text {func }}\end{array}$ & $1-W E R$ \\
\hline $\begin{array}{l}\text { 성능 } \\
\text { 효율성 } \\
M_{p e r}\end{array}$ & $\begin{array}{l}\text { 동일기능에 대해서 } \\
\text { 타 방식 처리 시간 } \\
\text { 음성인식 처리 시간 }\end{array}$ \\
\hline $\begin{array}{l}\text { 사용성 } \\
M_{u s e}\end{array}$ & $\begin{array}{l}\text { 동일기능에 대해서 } \\
\text { 타 방식 인터페이스 접근 노력 } \\
\text { 음성인식 인터페이스 접근 노력 }\end{array}$ \\
\hline $\begin{array}{l}\text { 신뢰성 } \\
M_{r e}\end{array}$ & $\frac{\text { 입력과 동일한 음성 인식 횟수 }}{100 \text { 회 입력 }}$ \\
\hline $\begin{array}{l}\text { 보안 } \\
M_{s e}\end{array}$ & $\begin{array}{l}\text { 음성모델 학습 } \mathrm{DB} \text { 암호화 } \\
\text { 보안강도 }\end{array}$ \\
\hline
\end{tabular}

최종 품질 평가를 위해서 표 6 과 같은 5 개의 품질 속성에 대해서 동일한 가중치를 적용하기 보다는 중요도에 따른 가중치를 적용해야 한다. 이는 항공기의 운용 조건 및 음성인식 환경에서 유사한 국방분야에 적용되는 인공지능 성격을 활 용해 가중치를 할당할 수 있다. 국방 인공지능은 모든 입력(전장) 상황에 대해서 강건하면서 신속 하게 결정을 내려야 한다[10]. 이러한 성격을 토 대로 품질 속성에 대해서 항공기 운용 환경에 대 해서 그림 3과 표 9와 같이 가중치를 적용할 수 있다. 


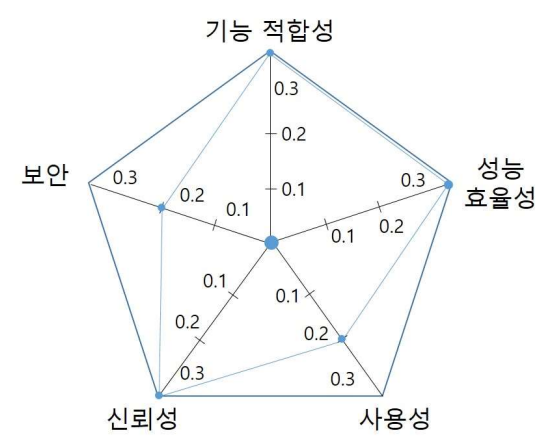

그림 3. 항공기 운용조건에 대한 가중치

Fig 3. Weigh for Aircraft operation environment

표 9. 품질 속성에 대한 가중치 할당 Table 9. Weight Assigned each Quality Attributes

\begin{tabular}{|c|c|}
\hline $\begin{array}{c}\text { 품질 속성별 } \\
\text { 가중치 }\end{array}$ & 가중치 값 \\
\hline $\begin{array}{c}\text { 기능 적합성 } \\
W_{f u n c}\end{array}$ & 0.3 \\
\hline $\begin{array}{c}\text { 성능 효율성 } \\
W_{p e r}\end{array}$ & 0.3 \\
\hline $\begin{array}{c}\text { 사용성 } \\
W_{u s e}\end{array}$ & 0.2 \\
\hline $\begin{array}{c}\text { 신뢰성 } \\
W_{r e}\end{array}$ & 0.3 \\
\hline 보안 & 0.2 \\
\hline$W_{s e}$ & 0.3 \\
\hline
\end{tabular}

따라서 각 Metric별 품질평가 수치는 수식 (1) 과 같이 각 Metric 항목별 가중치와 각 Metric 수치 간 곱으로 표현할 수 있다.

$$
Q_{n}=W_{n} \times M_{n} \cdots
$$

여기서 $W n$ 은 $\mathrm{n}$ 번째 품질 속성에 따른 가중 치, $M n$ 은 $\mathrm{n}$ 번째 품질속성에 따른 Metric을 의 미한다.

음성인식 전체 품질 평가를 위해서는 각 속성
별 품질평가 수치가 반영되어야 하므로 수식 (2) 와 같이 표현할 수 있다.

$$
Q_{V R}=\sum_{n=1}^{5} Q_{n} \quad \cdots
$$

여기서 $Q_{V R}$ 은 최종 음성인식 품질 평가 수 치이고, $Q_{n}$ 은 각 Metric 별 품질 평가 수치이 다. 즉, $Q_{V R}$ 는 각 품질평가 수치에 대한 최종 합계이다.

이러한 $Q_{V R}$ 에 대해서 값이 클수록 항공기에 최적화된 음성인식으로 판단할 수 있다.

\section{4 사례 연구를 통한 품질 평가 확인}

제안된 품질평가 확인을 위해서 다음 사례에 대해서 적용했다.

항공기 적용된 $\mathrm{A}$ 음성인식 시스템은 아래와 같이 동작된다.

- 교신 주파수 값 $100 \mathrm{MHz}$ 를 음성으로 명령, 설정한다.(음성입력 : “주파수 - 백메가”)

- 동일한 설정은 주파수 설정 키패드를 이용, 총 $4(1,0,0, \mathrm{MHz})$ 개의 버튼을 누르면 설정 가능하다.

- $\mathrm{A}$ 음성인식 시스템에 대한 해당 측정값은 아래와 같다.

WER : $25 \%$

$\bigcirc$ 음성인식 처리 시간 : 4초

$\bigcirc$ 음성인식 동일기능에 대한 스위치 조작 시 소요 시간 : 5 초

동일 음성명령에 대한 동일 음성인식 횟수 : 80회(100회 입력 기준)

$\bigcirc$ 음성모델 학습 $\mathrm{DB}$ 암호화 강도 : 112 비트

위의 측정 결과에 따라 해당 음성인식은 표 8 에 정의한 수식에 따라 Metric을 산정할 수 있다. 
$M_{\text {func }}=1-W E R=1-0.25=0.75$

$M_{p e r}=\frac{\text { 타방식처리 시간 }}{\text { 음성인식처리시간 }}=\frac{5 \text { 초 }}{4 \text { 초 }}=1.25$

$M_{u s e}=\frac{\text { 타방식 인터페이스 접근 노력 }}{\text { 음성인식 인터페이스 접근노력 }}$ $=\frac{4}{2}=2$

※ 4: $1,0,0, \mathrm{MHz}$ 버튼 총 4회 접근

※ 2 : 음성 “주파수”, “백메가” 2 회 접근

$M_{r e}=\frac{\text { 입력과 동일한 음성인식 횟수 }}{100 \text { 회 }}$ $=\frac{80 \text { 회 }}{100 \text { 회 }}=0.8$

$M_{s e}=0.3$ (보안강도 112 비트)

각 Metric별 품질평가 수치 $Q_{n}$ 은 수식 (1)에 의해서 항목별로 산출 가능하다.

$$
\begin{aligned}
Q_{\text {func }} & =W_{\text {func }} \times M_{\text {func }} \\
& =0.3 \times 0.75=0.225 \\
Q_{\text {per }} & =W_{\text {per }} \times M_{\text {per }} \\
& =0.3 \times 1.25=0.375 \\
Q_{\text {use }} & =W_{\text {use }} \times M_{\text {use }} \\
& =0.2 \times 2=0.4 \\
Q_{r e} & =W_{\text {re }} \times M_{\text {re }} \\
& =0.3 \times 0.8=0.24 \\
Q_{s e} & =W_{\text {se }} \times M_{\text {se }} \\
& =0.2 \times 0.3=0.06
\end{aligned}
$$

수식 (2)에 의해서 A 음성인식 시스템에 대한 품질 평가 수치 $Q_{V R}$ 은 아래와 같이 정량적인 값으로 산출할 수 있다.

$$
\begin{aligned}
Q_{V R} & =\sum_{n=1}^{5} Q_{n} \\
& =Q_{\text {func }}+Q_{\text {per }}+Q_{u s e}+Q_{r e}+Q_{\text {se }} \\
& =0.225+0.375+0.4+0.24+0.06 \\
& =1.3
\end{aligned}
$$

산출된 값의 품질 평가는 해당 시스템의 품질 평가 수치 최대값을 기준으로 $Q_{V R}$ 과 수치적 근 접성을 활용해 판단할 수 있다. 품질 평가 수치 최대값을 획득하기 위해서는 수식 (1)에 의해 각 속성별 가중치 최대값과 각 Metric의 최대값을 활용해 계산할 수 있다. 각 속성별 가중치 최대 값은 표 9와 같이 고정값이므로 각 Metric의 최 대값으로 품질 평가 수치 최대값을 산출할 수 있 다. 각 Metric의 최대값은 표 10 과 같다.

표 10. Metirc별 최대값

Table 10. Maximum Value each Metric of Quality Attributes

\begin{tabular}{|c|c|l|}
\hline 메트릭 & 최대값 & \multicolumn{1}{|c|}{ 설명 } \\
\hline$M_{f u n c}$ 최대값 & 1 & $\begin{array}{l}\text { WER이 0일 경우 } \\
\text { 최대값 산출 }\end{array}$ \\
\hline$M_{p e r}$ 최대값 & 2 & $\begin{array}{l}\text { 성능효율성 목표치 } \\
\text { (2배)로 가정한 최 } \\
\text { 대값 산출 }\end{array}$ \\
\hline$M_{u s e}$ 최대값 & 2 & $\begin{array}{l}\text { 사용성 목표치(2배) } \\
\text { 로 가정한 최대값 } \\
\text { 산출 }\end{array}$ \\
\hline$M_{r e}$ 최대값 & 1 & $\begin{array}{l}\text { 음성 인식 성공횟수 } \\
\text { 가 100회인 경우 최 } \\
\text { 대값 산출 }\end{array}$ \\
\hline$M_{s e}$ 최대값 & 1 & $\begin{array}{l}\text { 최대 보안강도 적용 } \\
\text { 시 최대값 산출 }\end{array}$ \\
\hline
\end{tabular}

따라서 음성인식 $\mathrm{A}$ 시스템의 최대 품질 평가 수치는 수식 (1)과 (2)를 통해 아래와 같이 산출 할 수 있다.

$$
\begin{aligned}
Q_{\text {Max }}= & (0.3 \times 1)+(0.3 \times 2)+(0.2 \times 2) \\
& +(0.3 \times 1)+(0.2 \times 1) \\
= & 1.8
\end{aligned}
$$

따라서 음성인식 $\mathrm{A}$ 시스템의 품질 평가 수치 $Q_{V R}$ 값은 $Q_{M a x}$ 값에 근접하므로 좋은 음성인 식 시스템으로 평가할 수 있다. 


\section{4. 결 론}

음성인식 기술은 현재 대중적으로 활용하는 기술이 되었고 인터넷과 연결되어 해당 서비스와 연계가 되어 음성인식의 장점을 적극 활용하고 있다. 방위산업, 특히 항공분야에서도 이러한 음 성인식을 바탕으로 조종사에게 많은 편익 기능을 제공할 수 있다. 하지만 항공분야는 항공기 운용 의 특수환경, 즉 고속운항에 따른 정확성과 신속 한 처리, 조종사 및 인원 탑승에 따른 안정성이 중요한 요소이다. 따라서 이러한 환경에 대해서 음성인식 적용을 위해 품질평가는 대단히 중요한 요소이다. 또한 품질평가를 위해 평가자의 주관 이 일부 개입하는 정성적인 평가가가 아닌 수치 적으로 산출되는 정량적 평가를 이용한 객관화가 중요하다. 이러한 평가를 만족하기 위해 음성인 식 기술과 ISO/IEC 25000을 이용해 평가 요소를 식별하였고 항공기 운용상황에 맞는 가중치로 최 적화 시킨, 항공기용 음성인식 품질 평가 모델을 제안하였다 사례 연구를 통해서 지표로 산출됨을 확인하였다. 평가에 대한 가중치는 항공기의 사 용 목적에 따라서 평가자 및 개발자, 사용자와 함께 변경가능 하여 탄력성 있게 적용가능하다.

\section{참 고 문 헌}

[1] 최지혜, 이선희, "음성인식 $\mathrm{AI}$ 비서 시장의

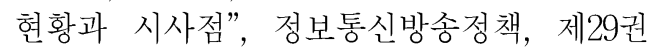
9호 통권 646호, http://www.kisdi.re.kr/ kisdi/fp/kr/publication/selectResearch.do?cm $\mathrm{d}=$ fpSelectResearch\&sMenuType $=2 \&$ control NoSer $=2 \&$ control $N o=14148 \&$ langdiv $=1$

[2] 최재호, 김훈태, "스마트폰 음성 인터페이스 사용 현황 및 사용자 인식에 대한 조사 연 구”, 한국전자거래학회지, v.21 no.4, 2016년, pp.29-40, http://dx.doi.org/10.7838/jsebs. 2016.21.4.029
[3] 한국산업기술평가관리원, "음성인식 가상비 서 기술 동향 및 전망", KEIT PD 이슈리포 트 2019-4월호 : 이슈1(음성인식 가상비서 기술 동향 및 전망), http://pdf.keit.re.kr/ sd7/view?permission=p\&elementId=GTLYr1 Jv2uAWUC1fMZZiuA\%3D\%3D\&cryptoPass $\mathrm{Yn}=\mathrm{N}$

[4] 김성우, 서민기, 오영환, 김봉규, "전투기용 음성명령 시스템에 대한 연구”, 한국항공우 주학회지, v.41, no.12, pp.1011-1017, http:// dx.doi.org/10.5139/JKSAS.2013.41.12.1011

[5] 유승우, 진영권, "항공기 인증을 위한 시스 템 안전성 평가", 항공진흥, 통권 제 42 호, http://www.airportal.go.kr/upload/library/jin 42_10\%EC\%9C\%A0\%EC\%8A\%B9\%EC\%9A $\%$ B0.pdf

[6] 박현신, 김성웅, 진민호, 유창동, "최신 기계 학습 기반 음성인식 기술 동향”, 전자공학회 지, v.41 no.3, pp.18-27, http://www.ndsl.kr/ ndsl/commons/util/ndslOriginalView.do?dbt $=\mathrm{JAKO \& cn}=\mathrm{JAKO} 201418960400803 \& \mathrm{oCn}=\mathrm{J}$ AKO201418960400803\&pageCode=PG11\&jou rnal=NJOU00290673

[7] 김승희, 김우제, "ISO 25000에 기초한 SW Life Cycle 별 응용SW 품질 상관관계 및 속성 중요도 분석”, 정보과학회논문지, 소프 트웨어 및 응용 V.41 no.2, 2014년, pp.112-127, http://www.ndsl.kr/ndsl/ commons/util/ndslOriginalView.do?dbt=JAK O\&cn=JAKO201417741960450\&oCn=JAKO2 01417741960450\&pageCode=PG11\&journal $=$ NJOU00291531

[8] D. Zubrow, "Software Quality Requirements and Evaluation", the ISO 25000 Series, PSM Technical Working Group, Carnegie Mellon Software Engineering Institute, Feb. 2004., http://www.psmsc.com/ Downloads/TWGFeb04/04ZubrowISO25000 SWQualityMeasurement.pdf

[9] 한국인터넷진흥원, "암호 알고리즘 및 키 길 이 이용 안내서", 한국인터넷진흥원 기술안 내서 가이드, https://www.kisa.or.kr/jsp/ common/downloadAction.jsp?bno=259\&dno= 82\&fseq $=1$ 
[10] 안창욱, 전문구, 신종원, 황치옥, 이기훈, "국 방 인공지능 AI 실증 기획 연구”, 온나라정 책연구, http://www.prism.go.kr/homepage/ entire/retrieveEntireDetail.do;jsessionid=B9E 0BE60CA603B058998B92920EB2CE8.node02? cond_research_name=\&cond_research_start_ date $=\&$ cond_research_end_date $=\&$ research_i $\mathrm{d}=$ 1290000-201700090\&pageIndex $=55 \&$ leftM enuLevel $=160$

\section{저 자 소 개}

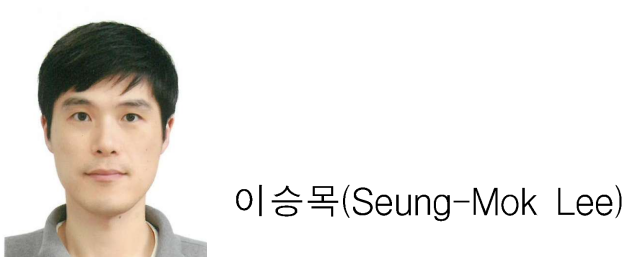

2009.2 경북대학교 전기전자컴퓨터학부 졸업 2009.1-현재 : 한화시스템 근무

<주관심분야> 항공전자, 임베디드, 소프트 웨어 품질 